\title{
A genome epidemiological study of SARS-CoV-2 introduction into
}

\section{Japan}

Tsuyoshi Sekizuka ${ }^{1 *}$, Kentaro Itokawa ${ }^{1}$, Masanori Hashino ${ }^{1}$, Tetsuro Kawano-Sugaya ${ }^{1}$, Rina Tanaka ${ }^{1}$, Koji Yatsu ${ }^{1}$, Asami Ohnishi ${ }^{2}$, Keiko Goto ${ }^{3}$, Hiroyuki Tsukagoshi ${ }^{4}$, Hayato Ehara $^{5}$, Kenji Sadamasu ${ }^{6}$, Masakatsu Taira ${ }^{7}$, Shinichiro Shibata ${ }^{8}$, Ryohei Nomoto $^{9}$, Satoshi Hiroi ${ }^{10}$, Miho Toho ${ }^{11}$, Tomoe Shimada ${ }^{12}$, Tamano Matsui ${ }^{12}$, Tomimasa Sunagawa $^{12}$, Hajime Kamiya ${ }^{12}$, Yuichiro Yahata ${ }^{12}$, Takuya Yamagishi ${ }^{12}$, Motoi Suzuki $^{12}$, Takaji Wakita ${ }^{13}$, and Makoto Kuroda ${ }^{1 *}$ and COVID-19 Genomic Surveillance Network in Japan.

1, Pathogen Genomics Center, National Institute of Infectious Diseases, Tokyo, Japan.

2, Sapporo City Institute of Public Health.

4 3, Ibaraki Prefectural Institute of Public Health, Ibaraki, Japan.

5 4, Gunma Prefectural Institute of Public Health and Environmental Sciences, Gunma, 6 Japan.

7 5, Saitama Prefectural Institute of Public Health, Saitama, Japan.

8 6, Department of Microbiology, Tokyo Metropolitan Institute of Public Health, Tokyo, 9 Japan.

0 7, Division of Virology and Medical Zoology, Chiba Prefectural Institute of Public 1 Health, Chiba, Japan.

2 , Microbiology Department, Nagoya City Public Health Research Institute, Aichi, 3 Japan.

4 9, Department of Infectious Diseases, Kobe Institute of Health, Kobe, Hyogo, Japan.

5 10, Division of Microbiology, Osaka Institute of Public Health, Osaka, Japan.

6 11, Fukui Prefectural Institute of Public Health and Environmental Science, Fukui, 7 Japan.

8 12, Infectious Disease Surveillance Center, National Institute of Infectious Diseases, 9 Tokyo, Japan.

0 13, National Institute of Infectious Diseases, Tokyo, Japan. 1

2 Correspondence: 1

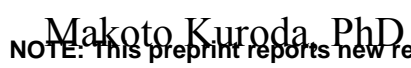


medRxiv preprint doi: https://doi.org/10.1101/2020.07.01.20143958; this version posted July 2, 2020. The copyright holder for this preprint

(which was not certified by peer review) is the author/funder, who has granted medRxiv a license to display the preprint in perpetuity.

It is made available under a CC-BY-NC-ND 4.0 International license.

34 Director, Pathogen Genomics Center, National Institute of Infectious Diseases.

35 1-23-1 Toyama, Shinjuku-ku, Tokyo 162-8640, Japan.

36 Phone: $+[81]-3-5285-1111$

37 E-mail: makokuro@niid.go.jp

38

39 
medRxiv preprint doi: https://doi.org/10.1101/2020.07.01.20143958; this version posted July 2, 2020. The copyright holder for this preprint

\section{$40 \quad$ Abstract}

\section{Background:}

42 After the first case of COVID-19 in Japan on 15 January 2020, multiple nationwide

43 COVID-19 clusters were identified by the end of February. The Japanese government

44 focused on mitigating emerging COVID-19 clusters by conducting active nationwide

45 epidemiological surveillance. However, an increasing number of cases appeared until

46 early April, many with unclear infection routes exhibiting no recent history of travel

47 outside Japan. We aimed to evaluate the severe acute respiratory syndrome coronavirus

482 (SARS-CoV-2) genome sequences from COVID-19 cases until early April and

49 characterise the genealogical networks to demonstrate possible routes of spread in

50 Japan.

\section{Methods:}

52 Nasopharyngeal specimens were collected from patients and a quantitative reverse 53 transcription polymerase chain reaction testing for SARS-CoV-2 was performed. Positive 54 RNA samples were subjected whole genome sequencing and a haplotype network 55 analysis was performed.

\section{Findings:}

57 Some of the primary clusters identified during January and February in Japan directly 58 descended from Wuhan-Hu-1-related isolates in China and other distinct clusters. 59 Clusters were almost contained until mid-March; the haplotype network analysis 60 demonstrated that COVID-19 cases from late March through early April may have caused 61 an additional large cluster related to the outbreak in Europe, leading to additional spread 62 within Japan. National self-restraint during February was effective in mitigating the 63 COVID-19 spread, but late action on stopping immigration and declaring national 64 emergency in Japan might be involved in the later increase in cases. 
medRxiv preprint doi: https://doi.org/10.1101/2020.07.01.20143958; this version posted July 2, 2020. The copyright holder for this preprint

(which was not certified by peer review) is the author/funder, who has granted medRxiv a license to display the preprint in perpetuity.

It is made available under a CC-BY-NC-ND 4.0 International license.

66 Genome surveillance suggested that at least two distinct SARS-CoV-2 introductions

67 from China and other countries occurred.

68 Funding: Japan Agency for Medical Research and Development.

69

70 
medRxiv preprint doi: https://doi.org/10.1101/2020.07.01.20143958; this version posted July 2, 2020. The copyright holder for this preprint

\section{Introduction}

72 The initial coronavirus disease 2019 (COVID-19) outbreak occurred in Wuhan, China

73 in late December 2019. It was caused by a new strain of beta coronavirus, known as the 74 severe acute respiratory syndrome coronavirus 2 (SARS-CoV-2) ${ }^{1-3}$. After the

75 identification of the first patient with COVID-19 in Japan on 15 January 2020, multiple

76 local COVID-19 clusters were identified nationwide by the end of February. The

77 Japanese government focused on identifying and mitigating emerging COVID-19

78 clusters before they could spread further. In an effort to contain these clusters and limit

79 the number of new cases, active, nationwide epidemiological surveillance of each

80 cluster was conducted in order to identify the close contacts of existing patients with

81 COVID-19. Japan has sustained a moderate spread by focusing on COVID-19 outbreak

82 clusters; however, an ever-increasing number of COVID-19 cases appeared until early

83 April, which made it difficult to identify all infection routes.

84 Although some of the COVID-19 clusters were successfully contained, the number of

85 cases continued to increase. As of 16 April, the Japanese government declared a

86 nationwide state of emergency in view of the worsening spread. To support the ongoing

87 epidemiological surveillance, we collaborated with the local public health institutes in

88 Japan (Supplementary Table S1) and conducted a whole genome sequencing of SARS-

89 CoV-2. Our goal was to apply genomic epidemiology to predict potential routes of

90 infection within or between clusters ${ }^{4}$. Thus far, multiple studies have been conducted to

91 demonstrate the COVID-19 spread under nationwide and global comparative genome

92 surveillance; as of 2 June, there were already 33,483 complete genomes publicly

93 available in the Global Initiative on Sharing All Influenza Data (GISAID) platform 5.

94 Some detailed reports have been conducted to highlight regional specific clusters and its

95 intra- and international spreads in the $\mathrm{US}^{6}, \mathrm{UK}^{7}$, Hungary ${ }^{8}$, Australia ${ }^{9}$, Denmark ${ }^{10}$,

96 Iceland ${ }^{11}$, and California ${ }^{12}$

97 In this study, we aimed to evaluate viral genome sequences from COVID-19 cases until

98 early April and characterise the genealogical networks to demonstrate possible routes of 99 spread in Japan. 
medRxiv preprint doi: https://doi.org/10.1101/2020.07.01.20143958; this version posted July 2, 2020. The copyright holder for this preprint

\section{Ethical approval and consent to participate}

102 The study protocol was approved by the National Institute of Infectious Diseases in Japan

103 (Approval No. 1091). It was conducted according to the principles of the Declaration of

104 Helsinki, in compliance with the Law Concerning the Prevention of Infections and

105 Medical Care for Patients of Infections of Japan. The ethical committee waived the need

106 for written consent since the study involved the viral genome sequencing. The personal

107 data related to the clinical information were anonymised, and our procedure is to not

108 request written consent for all patients with COVID-19.

109

110 Clinical specimens and reverse transcription polymerase chain reaction (RT-

111 qPCR) testing for COVID-19

112 Nasopharyngeal specimens were collected from patients and a quantitative RT-qPCR

113 testing for SARS-CoV-2 ${ }^{13,14}$ was performed at local public health institutes in Japan

114 (Supplementary Table S1). The positive RNA samples were subjected to whole genome

115 sequencing.

\section{Whole genome sequencing of SARS-CoV-2}

118 Whole genome sequences of SARS-CoV-2 were obtained by means of the PrimalSeq 119 protocol for enriching the cDNA of the SARS-CoV-2 genome using multiplex RT-PCR, 120 as proposed by the Wellcome Trust ARTIC Network ${ }^{15}$. We found two amplicons that 121 regularly showed low to zero coverage due to primer dimerization as described by 122 Itokawa et al. ${ }^{16}$. Therefore, we have modified the ARTIC Network's protocol for SARS-

123 CoV-2 genome sequencing by replacing some primers for the multiplex PCR ${ }^{17}$. The PCR

124 products in pool 1 and 2 from the same clinical sample were pooled, purified, and 125 subjected to Illumina library construction using a QIAseq FX DNA Library Kit (QIAGEN, 126 Hilden Germany). NextSeq 500 platform (Illumina, San Diego, CA) was used for 127 sequencing the indexed libraries. The next-generation sequencing (NGS) reads were 128 mapped to the SARS-CoV-2 Wuhan-Hu-1 reference genome sequence (29.9 kb ss-RNA; 129 GenBank ID: MN908947), resulting in the specimen-specific SARS-CoV-2 genome 
medRxiv preprint doi: https://doi.org/10.1101/2020.07.01.20143958; this version posted July 2, 2020. The copyright holder for this preprint

130 sequence by fully mapping on the reference. These mapped reads of SARS-CoV-2

131 sequences were assembled using A5-miseq v.20140604 ${ }^{18}$ to determine the full genome

132 sequence (Supplementary Table S2). The single nucleotide variations (SNV) sites and

133 marked heterogeneity were extracted by the read-mapping at $\geq 10 \times$ depth and from 99 -

$13429796 \mathrm{nt}$ region of Wuhan-Hu-1 genome sequence.

\section{Comparative genome sequence and SNV analyses}

137 The nearly full-length genome sequence $(\geq 29 \mathrm{~kb})$ of SARS-CoV-2 was retrieved from 138 the GISAID EpiCoV database in 28 April 2020, followed by multiple alignment using 139 MAFFT v7.222 ${ }^{19}$. The poorly aligned regions in $5^{\prime}$ and $3^{\prime}$ end were trimmed; we 140 determined that the core regions were from 99 to $29796 \mathrm{nt}$ position against Wuhan-Hu-1 141 genome sequences (GISAID ID, EPI_ISL_402125; GenBank ID, MN908947.3). Gap142 containing sequences in the core region were excluded; sequences of 2,887 isolates in 143 GISAID database were eventually used in subsequent analyses (isolate collection by 16 144 April 2020; submitted to GISAID by 27 April 2020; Supplementary Table S3). The 145 genome sequences were aligned using MAFFT software together with sequences 146 retrieved from databases, followed by extraction of SNV sites. The network analysis was performed using TCS $1.21^{20}$.

\section{Network graph visualization}

150 We had applied various visualization software for network graph visualization such as 151 Network, PopART, TCS, and Cytoscape. Nevertheless, all of the currently available 152 resources have not been suitable for the spatiotemporal dissection of SARS-CoV-2 153 genomic epidemiology and substantial on-site cluster eradication. Thus, we developed 154 Haplotype Explorer software to visualise the spatiotemporal pattern of SARS-CoV-2 155 infections based on network graphs (https://github.com/TKSjp/HaplotypeExplorer). 156 Haplotype Explorer allows for the analysis of network graphs spatiotemporally by 157 searching and filtering nodes interactively according to meta-data (e.g., collection date, 158 location, and accession number). Over 100 network graph images were captured daily 159 from the initial detection of SARS-CoV-2 (Wuhan-Hu-1; 31 December 2019) to 16 April, 
medRxiv preprint doi: https://doi.org/10.1101/2020.07.01.20143958; this version posted July 2, 2020. The copyright holder for this preprint

160 the day when Japan declared a national emergency. Interactive network file (html file;

161 Supplementary dataset 1) and the movie (mp4 file; Supplementary dataset 2) are available.

162

163 Comparison between outdoor activity and number of cases in Japan, the USA, and 164 the UK

165 We explored the relationships between outdoor activity, daily COVID-19 cases, and local 166 stay-at-home/shelter-in-place order/self-restraint campaigns in Japan, the USA (for New

167 York city and San Francisco Bay area), and the UK. The data shows population mobility 168 normalised to the value of 13 January 2020, which were retrieved from the COVID-19 169 mobility report provided by Apple (the data is available for a limited time only) $)^{21}$. The 170 values for walking were plotted for the three mentioned countries. Subsequently, we 171 plotted the mobility graph with daily and total COVID-19 cases, which were provided by 172 the National Institute of Infectious Diseases (currently the only Japanese data available)

$173^{22}$, Coronavirus Data in the United States (provided by New York Times) ${ }^{23}$, and 174 Coronavirus Source Data ${ }^{24}$.

175

\section{Role of the funding source}

177 The funding agencies had no role in the study design, data collection or analysis, decision 178 to publish, or manuscript preparation.

\section{Results and Discussion}

181 The nearly full-length genome sequences ( $\geq 29 \mathrm{~kb}, 2,887$ entries) of SARS-CoV-2 were 182 retrieved from the GISAID EpiCoV database (collection by April 16, 2020; submitted by 183 April 27, 2020) ${ }^{5}$. We determined the full genome sequences using 435 clinical specimens 184 in Japan collected until April 6, followed by performing a maximum-likelihood (ML) 185 phylogenetic analysis using genome-wide SNVs to trace potential infection routes (Fig. 186 1). After the identification of the first COVID-19 case in Japan on 15 January 2020, 187 multiple local COVID-19 clusters were observed. The genome sequences of Japanese 188 isolates were assigned based on phylogeny to China isolates from late February, but 189 nationwide dissemination seemed to already be present based on the ML phylogeny (Fig. 190 1). At least 4 or 5 main clusters are observed on the ML phylogeny, but this was not 
medRxiv preprint doi: https://doi.org/10.1101/2020.07.01.20143958; this version posted July 2, 2020. The copyright holder for this preprint

191 always adequately explained by the field epidemiological studies performed by local

192 public health centres about the patient's information such as nationality, being a Wuhan

193 returnee, and travel history.

194

195 Although phylogenetic trees are widely used for summarizing genealogies, one should 196 avoid a naïve interpretation of those results since the slow rate of SARS-CoV-2 evolution 197 and sampling bias of genomes could often lead to spurious conclusions ${ }^{25}$. In order to 198 decode the genealogies of the whole SARS-CoV-2 genome, we performed a haplotype network analysis describing ancestral relationships among the aforementioned genomic data sets and Wuhan-Hu-1 (GISAID ID, EPI_ISL_402125; GenBank ID, MN908947.3) as a potential most recent common ancestral (Fig 2).

202

203 Some of the primary clusters identified through January and February in Japan (2 red closed circles and magenta frames in Fig. 2) directly descended from the haplotype which was mostly seen in Wuhan-Hu-1-related isolates from China. Three other distinct clusters (additional 2 red closed circles and yellow frames in Fig. 2) were observed after the first introduction of Chinese isolates. Those four clusters of COVID-19 infections were assumed to be directly originated from the primary wave which occurred in China. Those clusters seemed to have been almost contained through the implementation of active surveillance in Japan until mid-March.

212 In contrast, the number of COVID-19 cases increased rapidly across Europe and North

213 America during early March (right half of Fig. 2), indicating a pandemic was occurring. 214 Concurrently, many sporadic COVID-19 cases were detected in Japan from the end of 215 March through early April. The haplotype network analysis demonstrated that an 216 additional large cluster (red closed circles and cyan frames in Fig 2) closely related to the 217 outbreak in Europe (originating in China or other countries) was predominantly observed 218 in Japan during early April, suggesting that they could have caused the increased spread 219 within Japan.

221 Analysis of whole genome sequences provides information that is useful for tracing the 222 spread of infection using genome-wide SNVs among clusters. To elucidate which Japan 223 political decisions (Fig. 3A, and Supplementary Table S4) and activities were effectively 
medRxiv preprint doi: https://doi.org/10.1101/2020.07.01.20143958; this version posted July 2, 2020. The copyright holder for this preprint

224 involved in the introduction of specific SARS-CoV-2 lineages, we characterised daily 225 COVID-19 case reports and a mobility index of people inferred from iPhone tracking 226 (Fig. 3B) in Japan, USA, and UK before and after the self-restraint campaign.

228 During the primary wave from China, international airports investigated potential patients 229 with COVID-19 using the keywords "Wuhan, Hubei, Zhejiang, and China" in early 230 February (Fig. 3A), and local public health centres were able to identify patients likely to

231 be infected with COVID-19 and their close contacts within location-specific clusters by 232 conducting active epidemiological surveillance. After the end of February, a national self233 restraint was requested in Japan, leading to significant reductions in activity observed 234 after the self-restraint was implemented. Although the situation in Japan had begun to 235 improve around mid-March, a large number of new patients with COVID-19 were 236 diagnosed, many of whom with unclear infection routes. Tracing the infection routes was 237 difficult because some Japanese cases had no recent history of travel to China or any other 238 country outside Japan.

239

240 During the national holidays from 20-22 March, a part of the population left their homes 241 to visit the cherry blossoms, which possibly increased mobility (Fig. 3B). It was 242 speculated that such a partial increase in activity at that time might have allowed for a 243 resurgence of the remaining lineage from the first introduction which had previously 244 circulated. The SARS-CoV-2 haplotype network analysis, however, suggested that the 245 second wave of COVID-19 cases in late March had a distinct origin from the first wave 246 lineage. The lineage of the second wave could have been imported by the returnees or 247 travellers from Europe, North America, or other countries ${ }^{26}$ (see the image in cyan 248 frame in Fig. 2), but not by the remaining Wuhan lineage. Considering the increasing 249 COVID-19 cases in Europe and the detection of imported cases in Japan, the Japanese 250 government decided to stop immigration from Europe in 27 March (Fig. 3A).

252 On the other hand, increased mobility in the USA and UK continued through early March, 253 possibly leading to a sharp increase in COVID-19 cases from mid-March (Fig. 3B). 254 Intriguingly, activity in the San Francisco Bay area slowed down earlier than in New 255 York; the additional 3 days taken by New York to implement stay-at-home/shelter-in256 place orders compared to San Francisco may explain the mitigated COVID-19 spread in 
medRxiv preprint doi: https://doi.org/10.1101/2020.07.01.20143958; this version posted July 2, 2020. The copyright holder for this preprint

(which was not certified by peer review) is the author/funder, who has granted medRxiv a license to display the preprint in perpetuity.

It is made available under a CC-BY-NC-ND 4.0 International license.

257 San Francisco.

258

\section{Conclusions}

260 This genome surveillance study suggested that at least two distinct SARS-CoV-2

261 introductions from China and other subsequent countries, including some in Europe, were

262 detected. To mitigate the next wave of COVID-19 in Japan, it is necessary to formulate a

263 more efficient containment strategy using real-time genome surveillance supporting

264 epidemiological field investigations and highlight potential infection linkages.

265

266

267 
medRxiv preprint doi: https://doi.org/10.1101/2020.07.01.20143958; this version posted July 2, 2020. The copyright holder for this preprint

\section{Data Availability Statement}

269 The new sequences have been deposited in Global Initiative on Sharing All Influenza

270 Data (GISAID) with accession IDs EPI_ISL_479792 to EPI_ISL_480227 (Table S2).

\section{Funding}

273 This study was supported by a Grant-in Aid from the Japan Agency for Medical

274 Research and Development (AMED) under Grant number JP20fk0108103,

275 JP19fk0108103 and JP19fk0108104.

276

\section{Acknowledgments}

278 We sincerely thank the COVID-19 Genomic Surveillance Network in Japan 279 (Supplementary Table S1) for the collection and transportation of clinical specimens. We 280 are particularly grateful to the staff of the National Institute of Infectious Diseases, Field 281 Epidemiology Training Program (FETP) team; the Ministry of Health, Labor and 282 Welfare; and local governments for their assistance with administrative matters, field 283 investigations, data collection, and laboratory testing.

284 We would like to thank all researchers who have kindly deposited and shared genomic 285 data on GISAID. A table with genome sequence acknowledgments can be found in 286 Supplementary Table S3.

\section{Author Contributions}

289 TS1, KI, WT, and MK designed and organised the genome study.

290 AO, KG, HT, HE, KS, MT, SS, RN, SH, MT, and COVID-19 Genomic Surveillance

291 Network in Japan (Table S1) performed the laboratory detection.

292 RT and MH performed the genome sequencing, and TS1, KI, TKS and KY performed the 293 genome analysis.

294 TS2, TM, TS3, HK, YY, TY, and MS contributed to the field epidemiological study.

295 MK wrote the manuscript. 
medRxiv preprint doi: https://doi.org/10.1101/2020.07.01.20143958; this version posted July 2,2020 . The copyright holder for this preprint

\section{Declaration of interests}

298 The authors declare that the research was conducted in the absence of any commercial or

299 financial relationships that could be construed as a potential conflict of interest.

\section{$301 \quad$ Supplementary Table S1}

302 Collaboration with local public health institutes in COVID-19 Genomic Surveillance

303 Network in Japan.

\section{Supplementary Table S2}

305 Summary of NGS reads and in silico data analysis.

\section{Supplementary Table S3}

307 All GISAID-available SARS-CoV-2 genomes $(\mathrm{n}=2,887)$.

\section{Supplementary Table S4}

309 Japanese immigration restriction programs.

\section{Supplementary dataset 1}

311 Interactive genomic network file (html format).

312 Supplementary dataset 2

313 Genomic network movie file (mp4 format).

314 
medRxiv preprint doi: https://doi.org/10.1101/2020.07.01.20143958; this version posted July 2, 2020. The copyright holder for this preprint (which was not certified by peer review) is the author/funder, who has granted medRxiv a license to display the preprint in perpetuity.

\section{Figure legends}

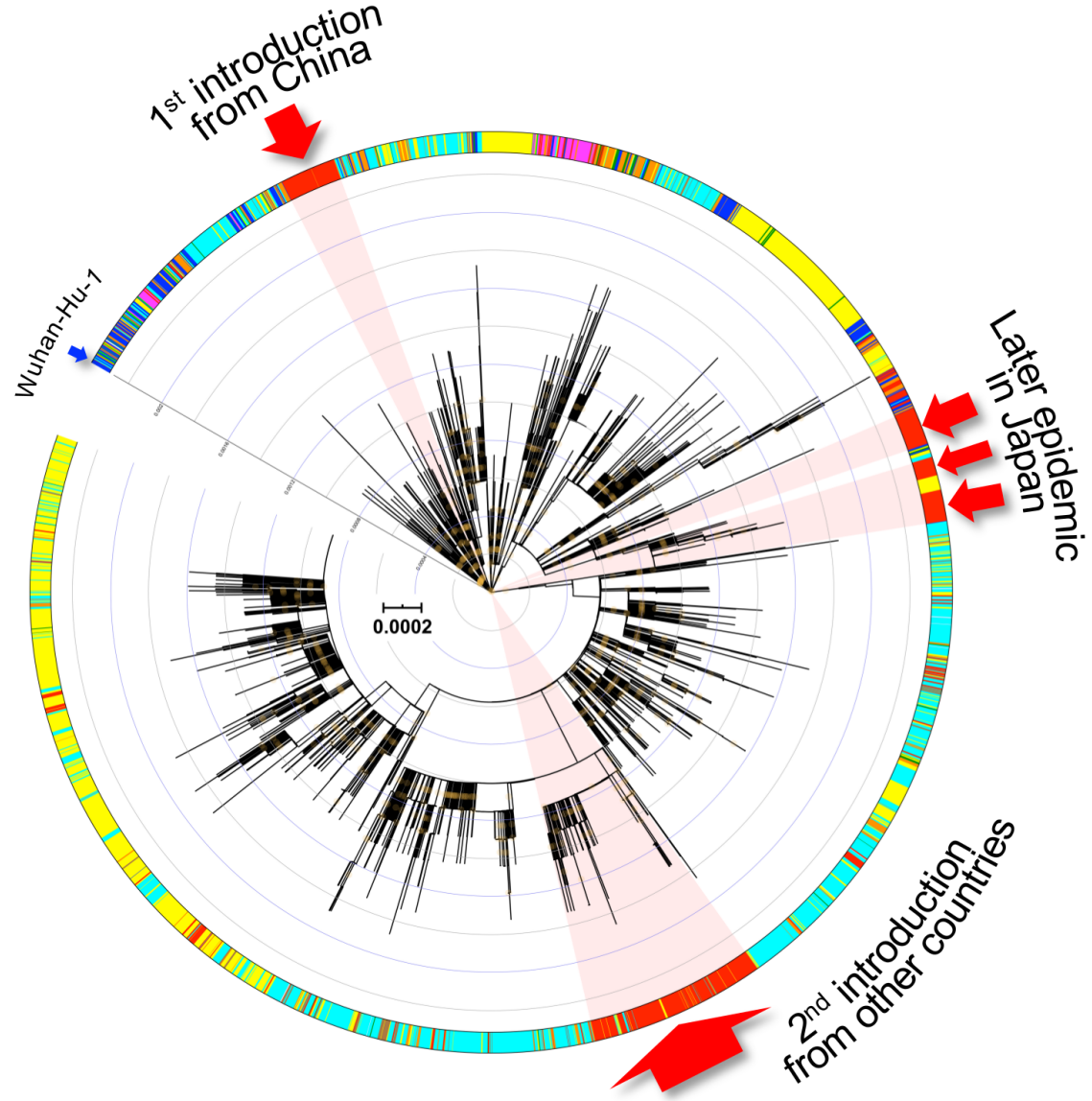

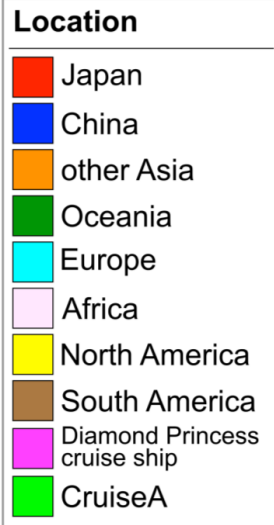

Bootstrap: $\geq 80 \%$ 3,322 isolates Total 2,212 SNVs

Fig. 1. A maximum-likelihood phylogenetic analysis using SARS-CoV-2 genome

323 In total, 2,212 SNVs were detected in 3,322 isolates, including Japanese isolates $(\mathrm{n}=435)$.

324 The maximum-likelihood phylogenetic tree was constructed using iqtree version 2.0.5 325 and Wuhan-Hu-1 (GISAID ID: EPI_ISL_402125) as an outgroup reference that is located 326 on the centre point of the radial tree for tree rooting. The geographic and sample 327 information are described in the colour schemes on the outer slot of the phylogenetic tree. 328 The cluster of remarkable outbreaks in Japan are highlighted in bright red. 
medRxiv preprint doi: https://doi.org/10.1101/2020.07.01.20143958; this version posted July 2, 2020. The copyright holder for this preprint (which was not certified by peer review) is the author/funder, who has granted medRxiv a license to display the preprint in perpetuity. It is made available under a CC-BY-NC-ND 4.0 International license.
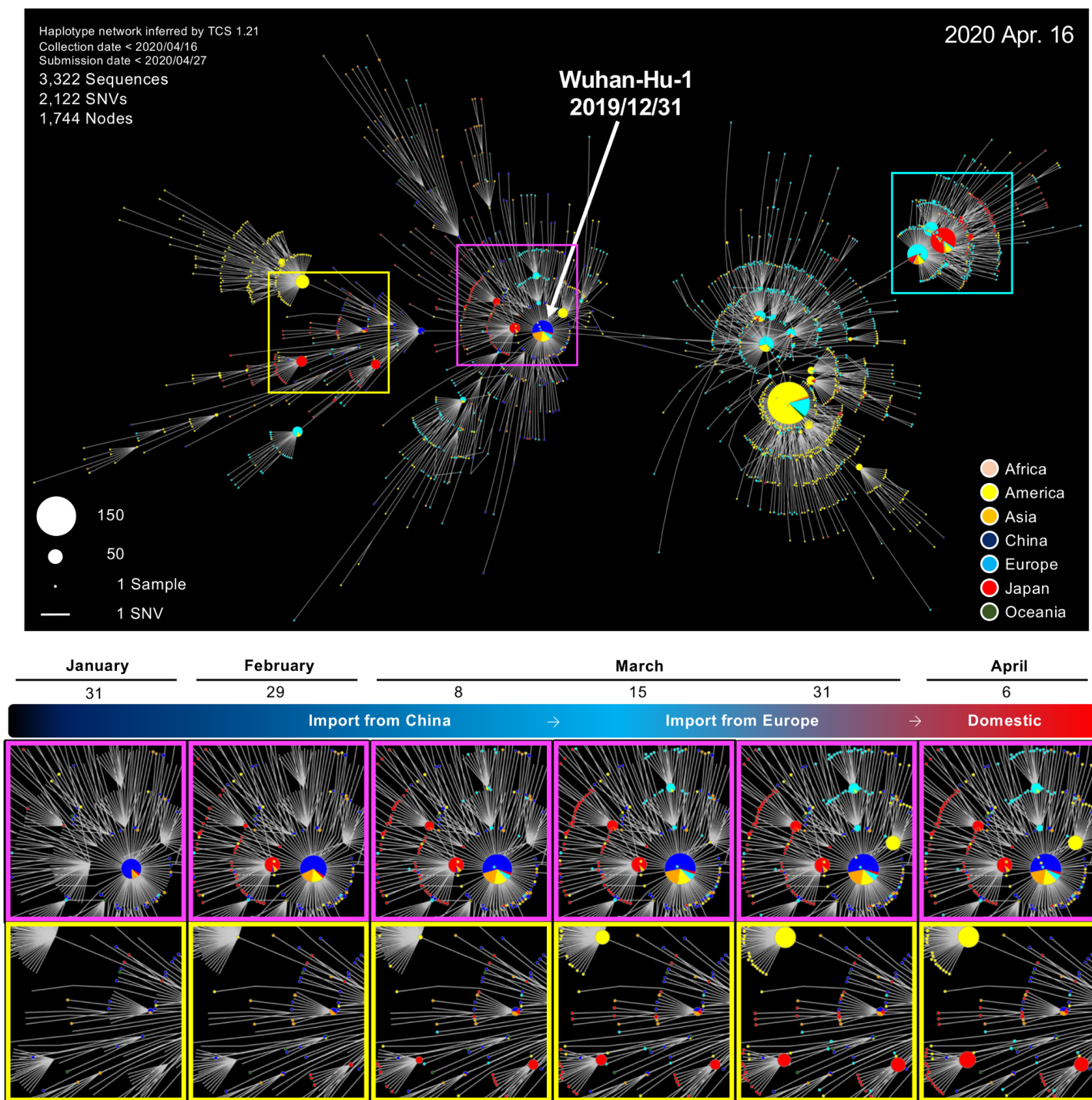

$\begin{array}{cc}\text { March } \\ 8 & 15\end{array}$
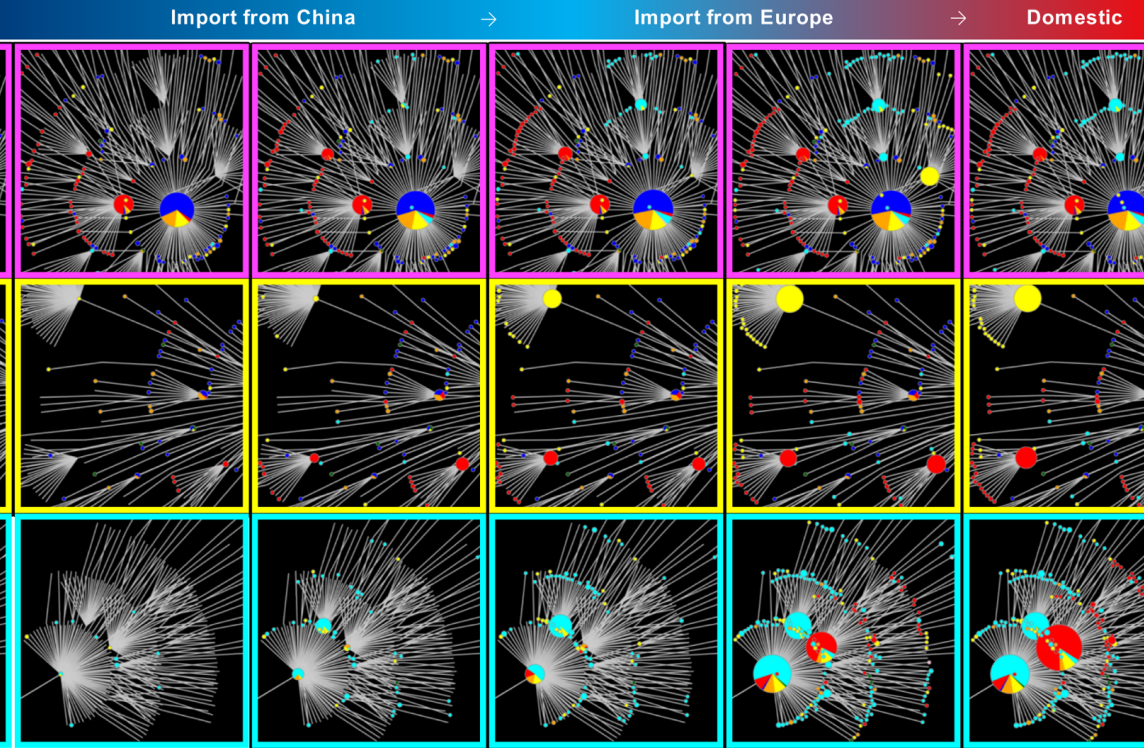

Fig. 2. Haplotype network analysis using genome-wide single-nucleotide variations

\section{3 of worldwide SARS-CoV-2 isolates.}

334 A) Whole-genome sequences of SARS-CoV-2 isolates in Japan ( $\mathrm{n}=435)$ were compared 335 to all GISAID-available SARS-CoV-2 genomes $(\mathrm{n}=2,887$, updated on 16 April 2020) 336 using TCS network analysis. SARS-CoV-2 disseminating from Wuhan City, China, at the 337 end of December 2019 (one of the potential origins of Wuhan-Hu-1) is plotted at the 338 centre of the haplotype network. B) Three plots of time-series cumulative COVID-19 339 cases were highlighted in each enclosed square to visualise the increasing incident 340 COVID-19 cases. 
medRxiv preprint doi: https://doi.org/10.1101/2020.07.01.20143958; this version posted July 2, 2020. The copyright holder for this preprint (which was not certified by peer review) is the author/funder, who has granted medRxiv a license to display the preprint in perpetuity. it is made available under a CC-BY-NC-ND 4.0 International license.

A

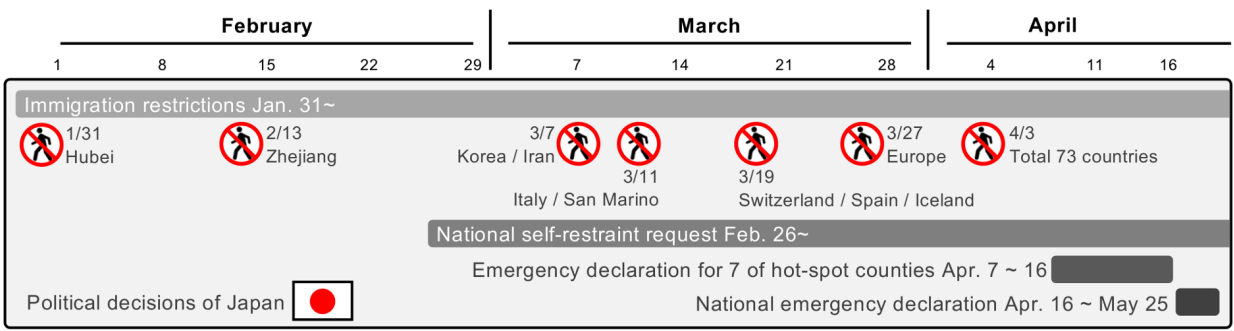

B

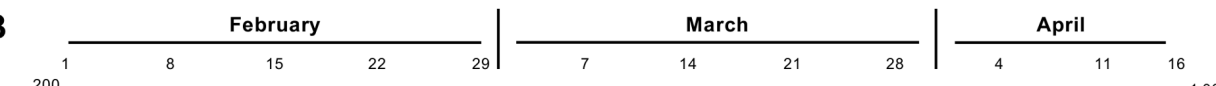
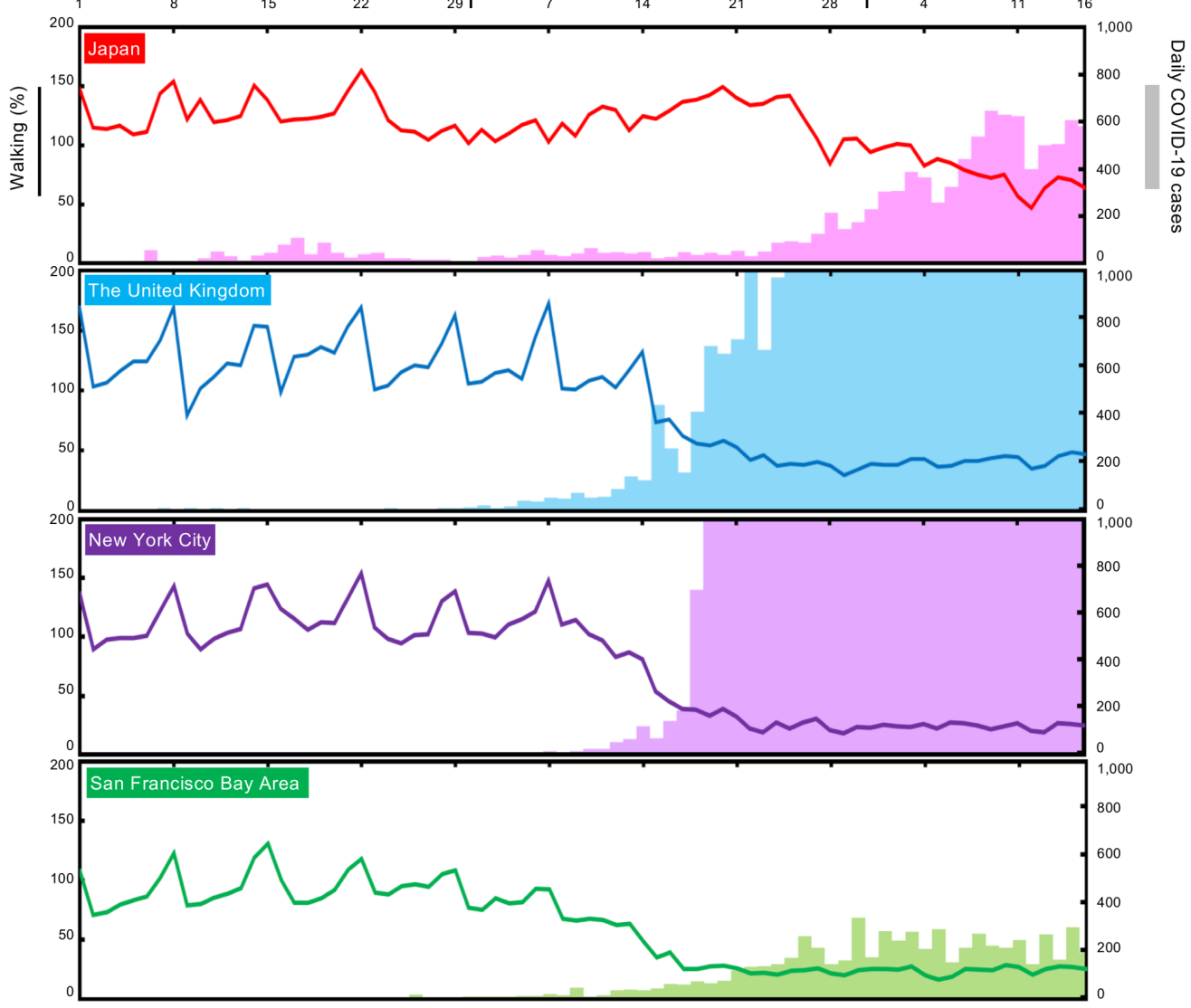

342 Fig. 3. Mobility index (walking) of people and daily COVID-19 cases in Japan, the

343 United Kingdom, New York city, and San Francisco Bay area.

344 A) Timeline of political decisions for the COVID-19 quarantine and national actions in

345 Japan (see also Supplementary Table S4). B) Mobility index of people and daily COVID-

34619 cases in Japan, the UK, and the USA (New York city and San Francisco Bay Area).

347 Solid lines indicate mobility index of people inferred from map application usages given

348 by Apple. Bar plot indicates daily COVID-19 cases. Notably, the data suggests that people

349 in Japan and San Francisco Bay Area collaborated with "stay-at-home" measures from

350 the end of February, which might have significantly reduced the expansion of SARS-

351 CoV-2 infections after late March 2020. 
medRxiv preprint doi: https://doi.org/10.1101/2020.07.01.20143958; this version posted July 2, 2020. The copyright holder for this preprint (which was not certified by peer review) is the author/funder, who has granted medRxiv a license to display the preprint in perpetuity.

\section{References}

354 1. Wu F, Zhao S, Yu B, et al. A new coronavirus associated with human respiratory 355 disease in China. Nature 2020.

356 2. Zhou P, Yang XL, Wang XG, et al. A pneumonia outbreak associated with a new coronavirus of probable bat origin. Nature 2020.

3. Coronaviridae Study Group of the International Committee on Taxonomy of V. The species Severe acute respiratory syndrome-related coronavirus: classifying 2019nCoV and naming it SARS-CoV-2. Nat Microbiol 2020.

4. https://www.niid.go.jp/niid/images/epi/corona/2019nCoV-02-200420.pdf.

5. https://www.gisaid.org/epiflu-applications/next-hcov-19-app/.

364 7. https://www.cogconsortium.uk/.

365 8. https://doi.org/10.1101/2020.05.06.080119.

366 9. https://doi.org/10.1101/2020.05.12.20099929.

367 10. https://doi.org/10.1101/2020.05.29.123612.

368 11. Gudbjartsson DF, Helgason A, Jonsson H, et al. Spread of SARS-CoV-2 in the Icelandic Population. N Engl J Med 2020.

370 12. Deng $\mathrm{X}, \mathrm{Gu} \mathrm{W}$, Federman $\mathrm{S}$, et al. Genomic surveillance reveals multiple introductions of SARS-CoV-2 into Northern California. Science 2020.

13. Shirato K, Nao N, Katano H, et al. Development of Genetic Diagnostic Methods for Novel Coronavirus 2019 (nCoV-2019) in Japan. Jpn J Infect Dis 2020.

14. Jung YJ, Park G-S, Moon JH, et al. Comparative analysis of primer-probe sets for the laboratory confirmation of SARS-CoV-2. bioRxiv 2020.

376 15. ARTIC Network protocol. https://articnetwork/ncov-2019.

377 16. https://www.biorxiv.org/content/10.1101/2020.03.10.985150v3

378 17. https://www.biorxiv.org/content/10.1101/2020.03.10.985150v3.

379 18. Coil D, Jospin G, Darling AE. A5-miseq: an updated pipeline to assemble microbial 380 genomes from Illumina MiSeq data. Bioinformatics 2015; 31(4): 587-9.

381 19. Katoh K, Standley DM. MAFFT multiple sequence alignment software version 7: 382 improvements in performance and usability. Mol Biol Evol 2013; 30(4): 772-80.

383 20. Clement M, Posada D, Crandall KA. TCS: a computer program to estimate gene genealogies. Mol Ecol 2000; 9(10): 1657-9. 
medRxiv preprint doi: https://doi.org/10.1101/2020.07.01.20143958; this version posted July 2, 2020. The copyright holder for this preprint

(which was not certified by peer review) is the author/funder, who has granted medRxiv a license to display the preprint in perpetuity.

It is made available under a CC-BY-NC-ND 4.0 International license.

385 21. https://www.apple.com/covid19/mobility.

386 22. https://www.niid.go.jp/niid/ja/diseases/ka/corona-virus/2019-ncov.html.

387 23. https://github.com/nytimes/covid-19-data.

388 24. https://ourworldindata.org/coronavirus-source-data.

389 25. https://doi.org/10.1101/2020.05.21.109322.

390 26. Sekizuka T, Kuramoto S, Nariai E, et al. SARS-CoV-2 Genome Analysis of Japanese

$391 \quad$ Travelers in Nile River Cruise. Front Microbiol 2020; 11: 1316.

392 